\title{
Study of Cracking Mechanism and Wear Resistance in Laser Cladding Coating of Ni-based Alloy
}

Zhenglei Yu ${ }^{1,2}$, Lunxiang Li ${ }^{3}$, Deqiang Zhang ${ }^{4}$, Guangfeng Shi ${ }^{3 *}$, Guang Yang ${ }^{5}$, Zezhou Xu ${ }^{1}$ and Zhihui Zhang ${ }^{1}$

\begin{abstract}
Nickel-based alloy coatings were widely used for the remanufacturing of dies and moulds by laser cladding, but the crack sensitivity would be increase due to the higher strength and hardness, which reduced the wear resistance of $\mathrm{Ni}$-based alloys. In this paper, Ni-based coatings with the addition of a plastic phase (an austenitic stainless net) were prepared using laser cladding technology, and the $\mathrm{CeO}_{2}$ was added in cladding layers. The cracking mechanism, microhardness, microstructure, phase composition, and wear properties were investigated. The relationship between thermal stress and the elastic and plastic fracture had been developed from the standpoint of fracture mechanics and thermal elastic fracture mechanics. The fracture criterion of the nickel-based coating was obtained, and the study has shown that the crack sensitivity could be reduced by decreasing the thermal expansion coefficient $\Delta a$. Thus, a new method was proposed, which the stainless steel nets were prefabricated on the substrate. It was found that the number of cracks reduced significantly with the addition of stainless steel net. When the stainless steel net with 14 mesh was added in Ni-based coatings, the average microhardness of nickel composite coating was 565 $\mathrm{HV}_{0.2}$ which was 2.6 times higher than that of the 45 steel substrate. Although the rare earth oxide $4 \mathrm{wt} . \% \mathrm{CeO}_{2}$ and stainless steel net were added in the Ni-based coating reducing the microhardness (the average microhardness is $425 \mathrm{HV}_{0.2}$ ), the wear resistance of it improved substantially. The wear volume of Ni-based composite coating was $0.56 \times 10^{-5} \mathrm{~mm}^{3} \cdot \mathrm{N}^{-1} \cdot \mathrm{m}^{-1}$, which was $85.1 \%$ lower than that of $45 \mathrm{steel}$. The experiment results have shown that the Nickel-based composite coating is equipped with low crack sensitivity and high abrasive resistance with austenitic stainless net and the rare earth oxide $4 \mathrm{wt} . \% \mathrm{CeO}_{2}$. This research offers an efficient solution to produce components with low crack susceptibility and high wear-resistance coatings fabricated by laser cladding.
\end{abstract}

Keywords: Laser cladding, Wear resistance, Crack sensitivity, Stainless steel net, Rare earth oxide

\section{Introduction}

It is well-known that abrasive wear is a severe problem to industrial components and equipment, resulting in energy consumption [1-3]. In order to prolong their service life, these components should be fabricated with coatings. Laser cladding is a surface modification technique creating a high-performance coating on the surface

\footnotetext{
*Correspondence: sgfcust@sina.com

${ }^{3}$ College of Mechanical and Electric Engineering, Changchun University

of Science and Technology, Changchun 130022, China

Full list of author information is available at the end of the article
}

of metallic material by a laser beam of high energy densities [4-8]. The technology offers unique superiority in terms of a material with high hardness and high melting point such as ceramic [9], NiTi alloys [10], and nickelbased superalloy $[11,12]$, etc. Besides, laser cladding is popularly used to manufacture dense metallic parts with high performance, which is applied in aerospace, automotive, and turbines, etc [13-17].

The Nickel-based alloy coatings fabricated by laser cladding have outstanding wear resistance and corrosion resistance $[7,18]$. In recent years, more and more scholars have made an achievement in fabricating 
Ni-based alloy coatings and nickel-based composite coatings to further enhance wear resistance. Wang et al. [19] indicated that wear volume of Ni-based alloy coatings with the addition of $\mathrm{Y}_{2} \mathrm{O}_{3}, \mathrm{CeO}_{2}$, and $\mathrm{La}_{2} \mathrm{O}_{3}$ could be reduced remarkably. Simultaneously, the defects, such as porosity, crack, and lack of fusion could be eliminated. In addition, it was worthy to point out that nano-sized particles could exhibit outstanding mechanical properties compared with micron-sized particles [20]. Zhao et al. [21] observed nanometer $\mathrm{La}_{2} \mathrm{O}_{3}$ could refine the microstructure of interdendritic dramatically. Tang et al. [22] reported that Ni60 cladding layers added nano-WC particles displaying high hardness and abrasive wear resistance than the Nickel-based alloy coatings without nano-WC particles. However, Nickelbased alloy coatings have high cracking sensitivity, owing to a large number of hard $\mathrm{Cr}$-rich precipitates and eutectic structures $[23,24]$.

Although Ni-based alloy coatings fabricated with rare earth, which plays a key role in producing grain refinement effect, might have superior anti-friction properties, coating's cracking susceptibility could not be reduced, which attributed to the existence of the eutectics network providing a route for crack growth [25]. Higher hardness and wear resistance could be obtained with the addition of hard ceramic particles, such as WC, TiC, and $\mathrm{SiC}$, but the hard phase added to a soft matrix could increase the brittleness of coatings at the same time [26, 27]. Some scholars had refocused on the methods to restrict crack formation. Zhai et al. [6] used alternating electromagnetic force produced by the effects of alternating current to refine grain structure. As a result, by using this approach, approximately $60 \%$ of cracks in Nickelbased alloy coatings could be eliminated. Dai et al. [28] suggested that coating's crack susceptibility could be decreased with the addition of Co element. Lu et al. [29] reported that the crack of nickel-based superalloy coating could be healed by laser remelting technology, which reduced grain sizes and quantity of carbonitride due to element segregation in the heat-affected zone and the coatings. The residual thermal stress is considered the driving force of crack to Ni-based alloy coatings, which usually produce stress concentration around the pores. In order to reduce crack susceptibility, a useful method could minimize pore area by optimized process parameters [30-32]. As a common method that, pre-heating had been applied to decrease crack susceptibility [3335]. These studies had been conducted mostly from rare earth additions, optimizing process parameters, and preheating the substrate to reduce the crack. However, the existence of micro-cracks of alloys will further promote the propagation of cracks during the surface abrasion process, thereby reducing wear resistance. Therefore, it is necessary to further consider the relationship between crack sensitivity and the wear performance of Nickelbased alloys.

This study focused on the mechanistic studies of cracking in the Ni-based coatings and presenting a fracture criterion for coatings from the viewpoint of fracture mechanics. Experiments, prefabricating metal nets on the subtract, were conducted to confirm the criterion of fracture by laser cladding. The influence rules of crack susceptibility on the variation of the mesh of metal nets were analyzed. Simultaneity, wear resistance of coatings by the addition of $\mathrm{CeO}_{2}$ were investigated on the corresponding mechanical properties, frictional coefficient, and wear volume. The present results will offer an efficient solution to produce components with low crack susceptibility and high wear-resistance coatings fabricated by laser cladding.

\section{Methodology on Crack Suppression}

\subsection{Crack Formation Mechanism}

During laser processing, the mismatch of expansion and shrinkage between the coating and the substrate is generally related to the difference in elastic modulus and thermal expansion coefficients. Based on thermoelasticity theory, the thermal stress $\sigma$ generated after solidification of the molten pool can be calculated by Eq. (1) [36]:

$$
\sigma_{x \max }=-f(x, L) E \Delta \alpha \Delta T,
$$

where $f(x, L)$ is a function of the analysis location and the initial length of the specimen; $E$ is the modulus of elasticity; $\Delta \alpha$ is the thermal expansion coefficient of deposited material; $\Delta T$ is the temperature difference between the analysis position and the restricted area.

In addition, a large temperature gradient along the deposition direction is generated in the molten pool, during which the temperature of the substrate is lower than that of the coatings owing to the good thermal conductivity of the substrate. Therefore, the cladding layer's shrinkage will be restrained by the substrate when the molten pool cools and solidifies, and the tensile stress is generated in the coating, which might bring a great tendency of cracking [36].

\subsection{Elastic and Plastic Fracture in Ni-based Alloy Coating}

By observing the cracks, the tensile stress leading to the fracture of the cladding layer is perpendicular to the direction of crack cracking, which belongs to the crack opening type.

The crack tip opening displacement is illustrated in Figure 1(a). The $A B$ segment of the crack surface is extended forward and intersects with the vertical line of tip $D$ at point $E$. The crack opening displacement $\delta$ is measured by $2 E D$. 


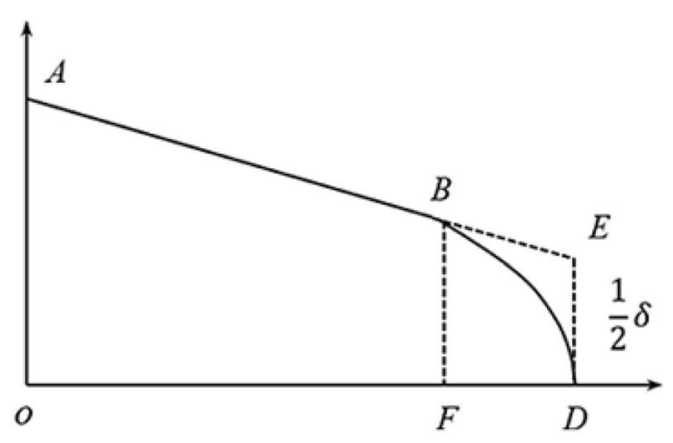

(a)

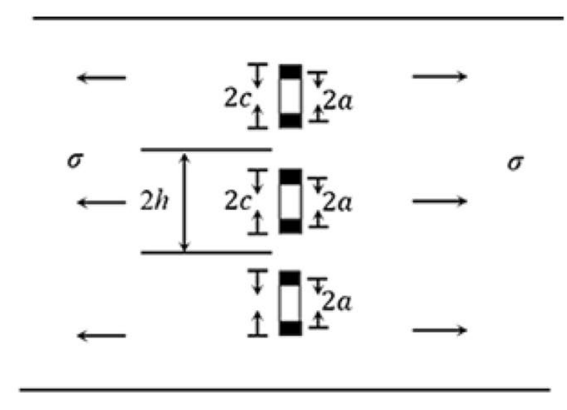

(b)

Figure 1 Cracking mechanism of Ni-based coating [37]: (a) critical opening displacement, (b) microcracks of coating

After cladding finished, very high residual tensile stress existed, and the cracks in the cladding layer are caused by the expansion of microcracks under residual tensile stress. It is assumed that there are infinite microcracks of equal length in the direction perpendicular to the scanning direction. The crack length is $2 a$, and the interval between adjacent cracks is $2 h$; the uniform tensile stress in the scanning direction is $\sigma$; the length of microcrack and its simplified plastic zone is $2 c=2 a+2 R$, a schematic illustration of the microcracks of the coating as shown in Figure 1(b). Cracking occurs when the crack opening displacement reaches the critical value $\delta_{c}$. At this time, the critical tensile stress can be calculated by Eq. (2) [37].

$$
\sigma_{s c}=\frac{\delta_{c} \pi E}{8 \sin \int_{\theta}^{\pi / 2} \frac{\cos X}{\sqrt{1-\sin ^{2} \alpha \sin ^{2} X}} \ln \left[\frac{\sin (X+\theta)}{\sin (X-\theta)}\right] \mathrm{d} X} .
$$

\subsection{Fracture Criterion of Nickel-based Coating}

The thermal stress of coating is expressed in two forms, $\Delta \alpha<0$, when the thermal expansion coefficient of the substrate is less than that of the cladding layer, and the coating is subjected to tensile stress. On the contrary, $\Delta \alpha>0$ when the thermal expansion coefficient of the substrate is higher than that of the cladding layer, and the coating is subjected to compressive stress. In order to protect Ni-based coating from cracking, it should be ensured that the maximum tensile stress $\sigma_{x \max }$ in the nickel-based coating is less than the critical tensile stress $\sigma_{s c}$ when there exists crack tendency in cladding layers. According to Eqs. (1) and (2), the micro-crack propagating condition can be described as follows: where, $\alpha=\frac{\pi c}{2 h}, \sin \theta=\frac{\sin (\pi a / 2 h)}{\sin \alpha}, \sin X=\frac{\sin (\pi x / 2 h)}{\sin \alpha}$.

Eq. (3) presents the factors that influence the microscopic cracks, including material thermophysical parameters $(E, \Delta \alpha, \Delta T)$, specimen length, the critical crack opening displacement when cracking occurs. In terms of crack susceptibility, the majority of these researches mainly focused on temperature gradient $\Delta T[38,39]$. The authors conclude that preheating of the matrix seemed to be an effective method for reducing the residual stress. However, there is little information about the thermal expansion coefficient on cracks sensibility. Related pieces of literature revealed that the thermal expansion coefficient is the main factor affecting the distortion and residual stresses while the impact of the elastic is relatively tiny. Hence, this paper focuses mainly on the thermophysical parameters $\Delta \alpha$ [40]. Cracks could be suppressed by reducing the absolute difference of thermal expansion coefficient between the $\mathrm{Ni}$ based coating and the substrate.

\section{Experiment Procedures}

\subsection{Initial Materials}

A medium carbon steel plate $(0.45 \mathrm{wt} . \% \mathrm{C})$ was selected as the substrate material, and its dimension was $55 \mathrm{~mm} \times 37 \mathrm{~mm} \times 10 \mathrm{~mm}$. 304 stainless steel net with eight different mesh (8 mesh, 10 mesh, 12 mesh, 14 mesh, 16 mesh, 20 mesh, 24 mesh, and 30 mesh, respectively) were selected for an experiment. To demonstrated the detail of the mesh, a list was established in Table 1. The chemical composition of the 45 steel and the 304 stainless steel net was shown in Table 2 . Ni60 powders with a particle size of $40-80 \mu \mathrm{m}$ were used as the raw powder. The chemical composition of the powder is listed in Table 3. The $\mathrm{CeO}_{2}$ particles with the contents of $4 \%$ were adsorbed

$$
-f(x, L) E \Delta \alpha \Delta T<\frac{8 \delta_{c} \sin \theta}{\pi} \int_{\theta}^{\pi / 2} \frac{\cos X}{\sqrt{1-\sin ^{2} \alpha \sin ^{2} X}} \ln \left[\frac{\sin (X+\theta)}{\sin (X-\theta)}\right] \mathrm{d} X,
$$


Table 1 The detail of 304 stainless steel

\begin{tabular}{llllllll}
\hline Nets $($ mesh) & $\mathbf{8}$ & $\mathbf{1 0}$ & $\mathbf{1 2}$ & $\mathbf{1 4}$ & $\mathbf{1 6}$ & $\mathbf{2 0}$ & $\mathbf{3 0}$ \\
\hline Wire diameter $(\mathrm{mm})$ & 0.4 & 0.35 & 0.32 & 0.3 & 0.27 & 0.25 & 0.23 \\
\hline
\end{tabular}

Table 2 Chemical composition of 45 steel and 304 stainless steel net (wt\%)

\begin{tabular}{|c|c|c|c|c|c|c|c|c|}
\hline Elements & $\mathrm{C}$ & $\mathrm{Si}$ & Mn & $P$ & $S$ & $\mathrm{Cr}$ & $\mathrm{Ni}$ & $\mathrm{Fe}$ \\
\hline 45 steel & $0.42-0.5$ & $0.17-0.37$ & $0.5-0.8$ & $\leq 0.035$ & $\leq 0.035$ & $\leq .25$ & $\leq 0.28$ & Balance \\
\hline 304 stainless steel net & 0.15 & 0.8 & 0.2 & & $\leq 0.03$ & $17.5 \sim 18.5$ & $8 \sim 12$ & Balance \\
\hline
\end{tabular}

Table 3 Chemical composition of Ni60 powders (wt\%)

\begin{tabular}{llllllll}
\hline Elements & C & Cr & Si & W & Fe & B & Ni \\
\hline Content \% & 0.80 & 15.50 & 4.00 & 3.00 & 15.00 & 3.50 & Balance \\
\hline
\end{tabular}
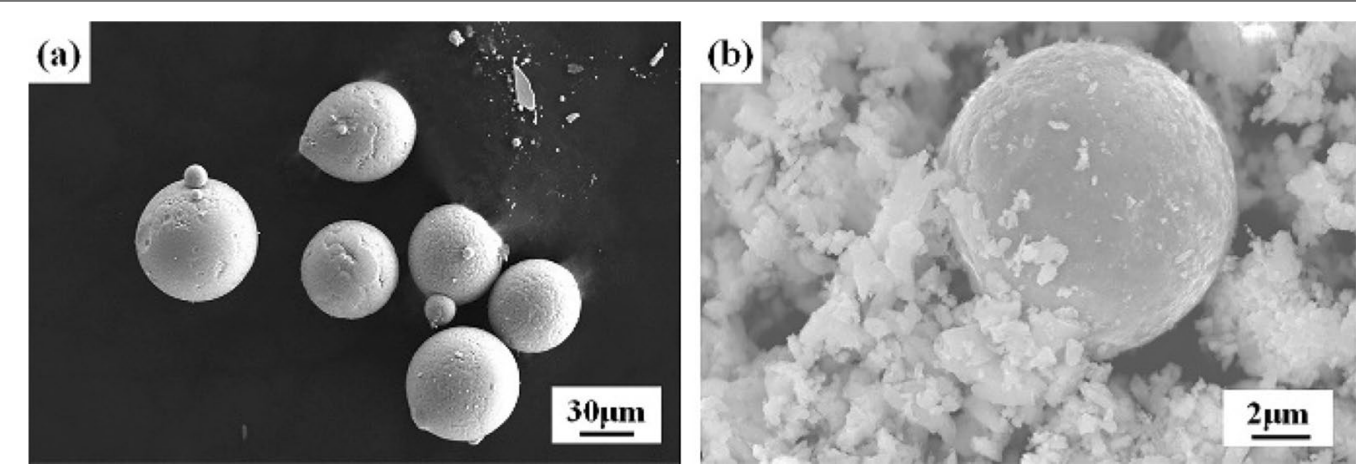

Figure 2 SEM micrographs: (a) Ni60 powders, (b) Ni60 powders with the addition of $4 \% \mathrm{CeO}_{2}$

on the Ni60 powders by mechanical ball grinding, and the morphology of two kinds of powders was shown in Figure 2.

\subsection{Experiment Apparatus and Process Parameters}

Ni-based composite coatings were performed on the LDM-800 laser additive manufacturing system built by Shenyang Aerospace University, as schematically shown in Figure 3. It consists of a $6 \mathrm{~kW}$ IPG fiber laser, a threeaxis motion execution system, a three-bin coaxial powder feeder (RC-PGF-D3), a coaxial powder feeding system with a Precitec laser cladding head (YC52), and an oxygen analyzer and control system. Pure argon with 99.99\% purity was used to deliver the powders and shield the molten pool from oxidation, which ensured the oxygen level was below $50 \mathrm{ppm}$. The reciprocating scanning strategy was adopted, and the single-track cladding layer length was $35 \mathrm{~mm}$. The process parameters of laser cladding were shown in Table 4. Before the experiment, the powder was dried in a vacuum oven at $80{ }^{\circ} \mathrm{C}$ for $8 \mathrm{~h}$ in order to increase fluidity. The substrate was ground and polished with sandpaper to remove the oxide layers, then the substrate was cleaned with ethanol. The 304 stainless steel net was washed with acetone to remove oil and then placed on the substrate.

\subsection{Characterization of the Coating}

After the experiments, cross-sections of all coatings were obtained by using the wire cutting machine, then the specimens were polished with $400 \#$ to $1500 \#$ grit sandpapers, and the microstructure was observed by an etchant $\left(\mathrm{H}_{2} \mathrm{O}\right.$ and $\mathrm{HNO}_{3}$ and $\mathrm{HF}$ with a ratio of $\left.7: 3: 1\right)$. The microstructure of coatings was studied and analyzed by metallographic microscope (MR5000). Zeiss sigma500 scanning electron microscope (SEM) equipped with an energy dispersive spectrometer (EDS) was employed to further confirm the microstructure and identify the chemical compositions of the coatings. The phase 


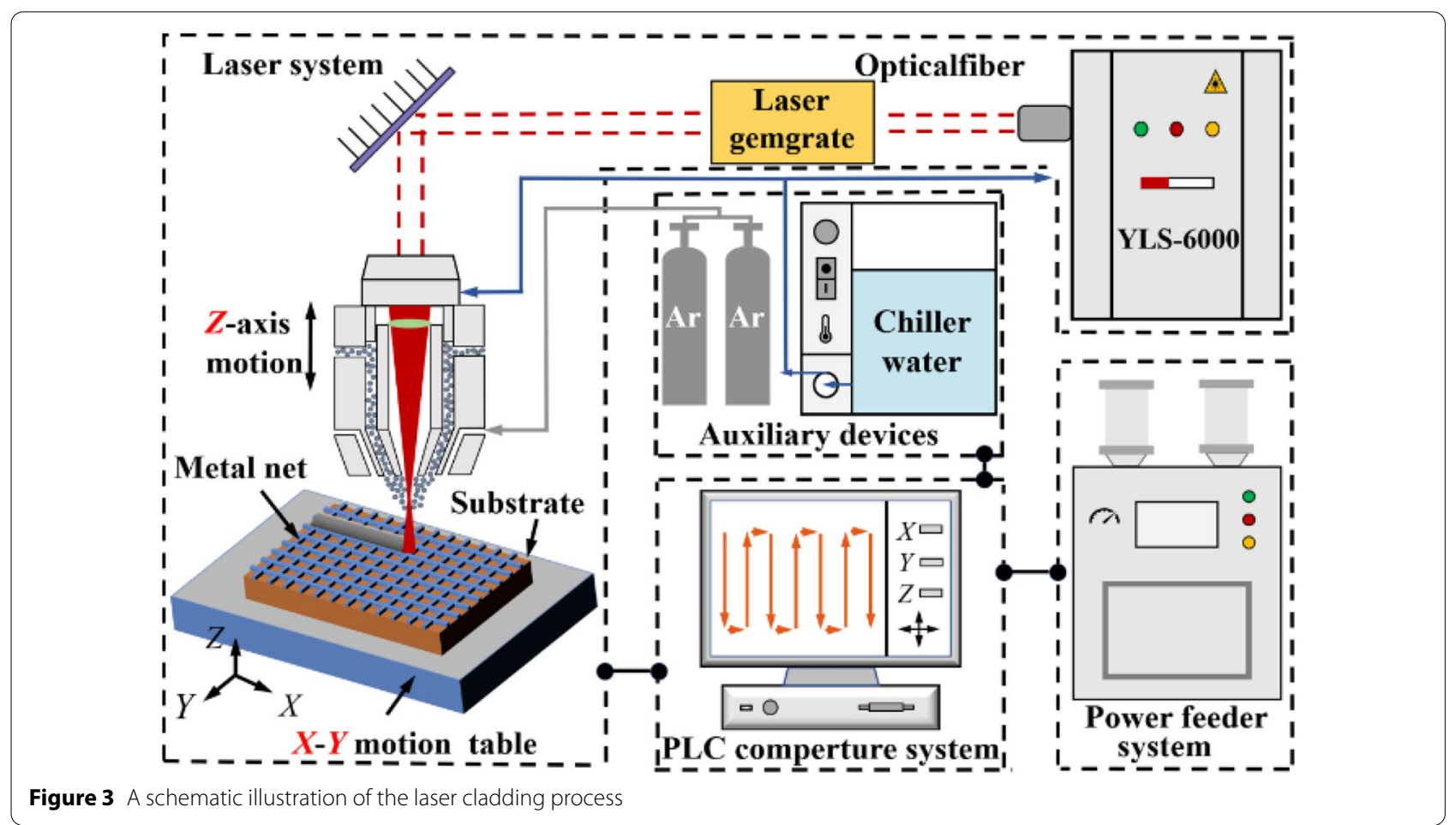

Table 4 Parameters of experiments

\begin{tabular}{lllll}
\hline $\begin{array}{l}\text { Laser } \\
\text { power } \\
\text { LP }(\mathbf{W})\end{array}$ & $\begin{array}{l}\text { Scanning } \\
\text { speed } \\
\text { SS }\left(\mathbf{m m} / \mathbf{s}^{-1}\right)\end{array}$ & $\begin{array}{l}\text { Powder } \\
\text { feeding rate } \\
\text { PFR }(\mathbf{g} / \\
\left.\mathbf{m i n}^{-1}\right)\end{array}$ & $\begin{array}{l}\text { Defocusing } \\
\mathbf{D}(\mathbf{m m})\end{array}$ & $\begin{array}{l}\text { Overlap rate } \\
H(\%)\end{array}$ \\
\hline 2100 & 8 & 6.6 & 14 & 50 \\
\hline
\end{tabular}

constitution of the cladding layer was performed using $\mathrm{D} / \mathrm{max}-2500 / \mathrm{PC}$ X-ray diffraction (XRD) with a copper target, and the range of diffraction angle $(2 \theta)$ was selected as $10^{\circ}-90^{\circ}$, X-ray tube high voltage: $40 \mathrm{kV}$, X-ray light tube current: $100 \mathrm{~mA}$. The XRD was implemented with a voltage of $40 \mathrm{kV}$, a current of $30 \mathrm{~mA}$, a continuous scanning speed of $8^{\circ} / \mathrm{min}$, and scanning from $10^{\circ}$ to $90^{\circ}$. The microhardness of cladding layers from the surface to the bottom was tested using an HVS-1000 Vickers microhardness tester with a loading force of about $0.98 \mathrm{~N}$ for $10 \mathrm{~s}$. One point was measured vertically every $0.1 \mathrm{~mm}$ at the cladding layer, each point was measured three times, and the final microhardness was the average value of measurements. The friction and wear tests were carried out on the MS-G5000 wear experimental machine, and the $\mathrm{Si}_{3} \mathrm{~N}_{4}$ balls were employed as friction pairs with a diameter of $5 \mathrm{~mm}$. The tests were conducted with a rotation speed of $200 \mathrm{r} / \mathrm{min}$ and a radius of $5.5 \mathrm{~mm}$, and 45 min friction tests with a $3 \mathrm{~N}$ normal load. The wear tracks after the $310 \mathrm{~m}$ sliding test were observed with a Keyence Digital Microscope VHX-500F. The wear volumes were assessed by the Alpha-Step D-100 profilometer.

\section{Results and Discussion}

\subsection{Effect of the Stainless Steel Net on Cracks and Wear Resistance of Nickel-based Composite Coatings \\ 4.1.1 Macroscopic Morphology Analysis of Nickel-based Composite Coating}

When the cladding layers were detected by dye penetrant test, there are transverse and longitudinal cracks in the Ni-based coating without the net, as illustrated in Figure 4. This is attributed to the thermal stresses that develop during solidification acting on grain boundaries, which is the main cause of cracking tendency. It is believed that cracks occur when the stress exceeds the yield limit of materials. It is well known that Austenitic stainless steel offers a comprehensive property of lower yield strength, better antioxidant properties, strong toughness, and weldability. The stainless steel nets were prefabricated on the substrate before the laser cladding experiment to obtain the coating $\mathrm{Ni}$-based composite coating, which was achieved after solidification. Experimental results showed that the 304 stainless steel net $\left(7 \times 10^{-6}-21 \times 10^{-6} / \mathrm{K}\right)$ on the substrate with different mesh leading to the cracks in the cladding layer decreased. Since the thermal expansion coefficient of 304 stainless steel net is higher than that of the 45 steel 

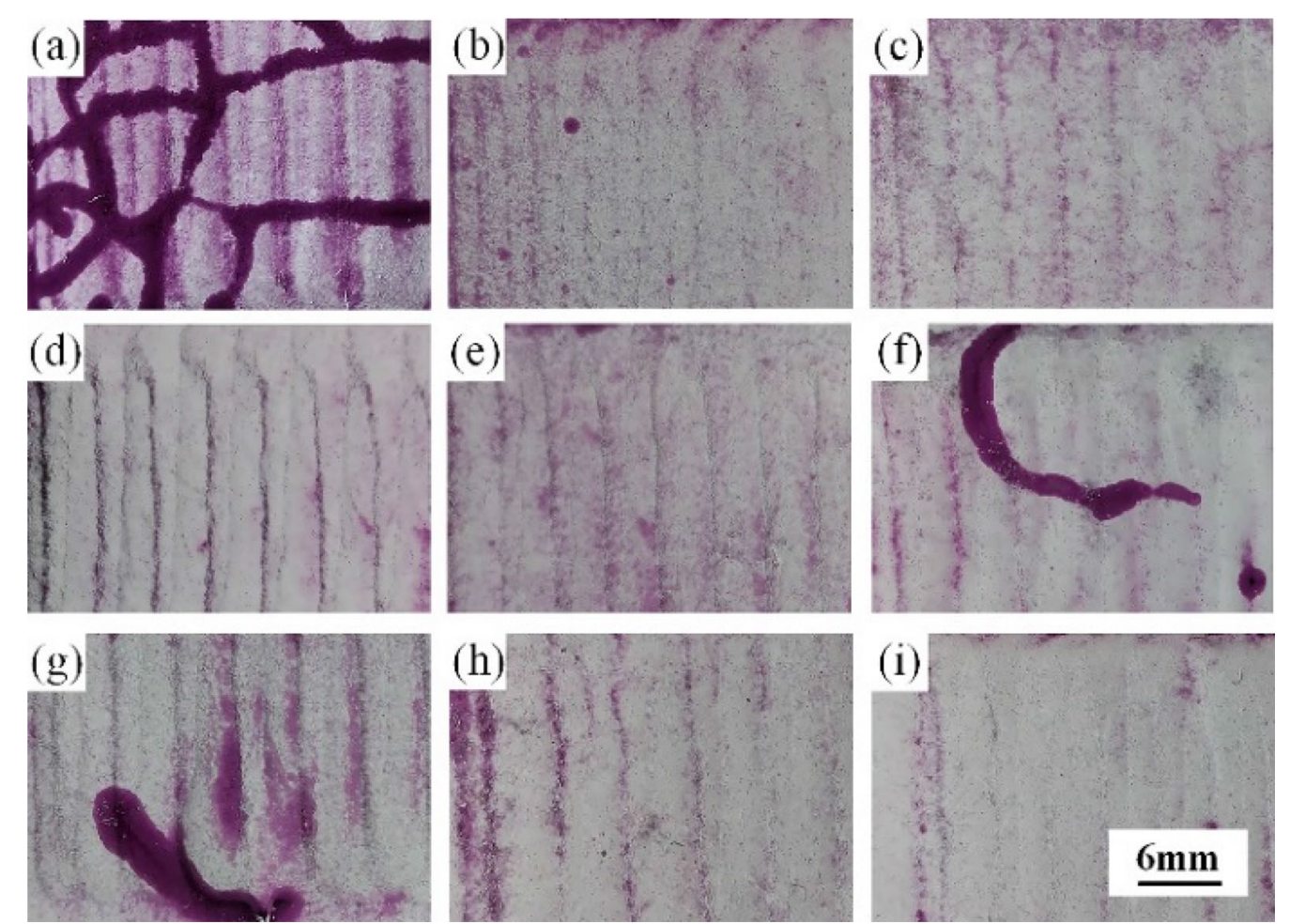

Figure 4 Crack observation by dye penetrant test: (a) Ni60, (b) Ni60 coating +8 mesh, (c) Ni60 coating +10 mesh, (d) Ni60 coating + 12 mesh, (e) Ni60 coating +14 mesh, (f) Ni60 coating +14 mesh, (g) Ni60 coating +20 mesh, (h) Ni60 coating +24 mesh, (i) Ni60 coating +30 mesh

$\left(11.9 \times 10^{-6}-13.1 \times 10^{-6} / \mathrm{K}\right)$. The stainless steel net, which was prefabricated on the surface of 45 steel substrates, can be regarded as a part of the substrate. At this time, the overall thermal expansion coefficient $\alpha_{0}=$ $\left(\alpha_{45}+\alpha_{304}\right)$ is greater than 45 steel. The absolute difference between the thermal expansion coefficient of the substrate after pre-fabricated the 304 stainless steel net and the Ni-based coating $\left(13.9 \times 10^{-6}-20 \times 10^{-6} / \mathrm{K}\right)$ decrease. From the above Eq. (2), the thermal stress of the cladding layer decreased, which led to reduce the crack sensitivity. However, there still existed cracks in $\mathrm{Ni}$-based composite coating with the addition of stainless steel nets of 16 mesh and 24 mesh. It demonstrated that the mesh number of the net is not the larger the better, nor the smaller the better. There exist a critical range to inhibit both the initiation and growth of the crack.

\subsubsection{Analysis of Cross-section Morphology of Nickel-based Composite Coating}

From Figure 5, some large pores exist in Ni-based composite coating with 8 mesh stainless steel net prefabricated on the substrate. Because there is a gap between the stainless steel net and the substrate, when the melting pool rapidly solidified, the gas in the gap can not be eliminated in time, forming pores. Compared with the cross-section morphology of Ni-based coating without the net, there was incomplete melting stainless steel wire in the Ni-based composite coating which the stainless steel net was prefabricated on the substrate with 10 mesh, and the presence of microcracks in the Ni-based composite coating which the stainless steel net with 12 mesh was prefabricated on the substrate. However, there were no obvious cracks or pores appeared in the composite coating, which the stainless steel net with 14 mesh was prefabricated on the substrate. It was found that there were small cellular pores in the nickel-based composite coating which the stainless steel net with 24 mesh and 30 mesh were prefabricated on the substrate through an optical microscope. When the specimen is subject to external forces, the existence of porosity has a positive effect on crack propagation, improving the crack sensitivity and decreasing the mechanical property of specimens. The above studies suggested that the precipitating gas hole existed in the nickel-based composite coating, and the gas content in a molten solute increased during the solidification of molten metal and the gas that precipitated near the bottom of grain boundaries. Similarly, it has a large driving force to precipitate gas. The solute of lower solubility is enriched at the intergranular phase, which provides geometric stabilization for 

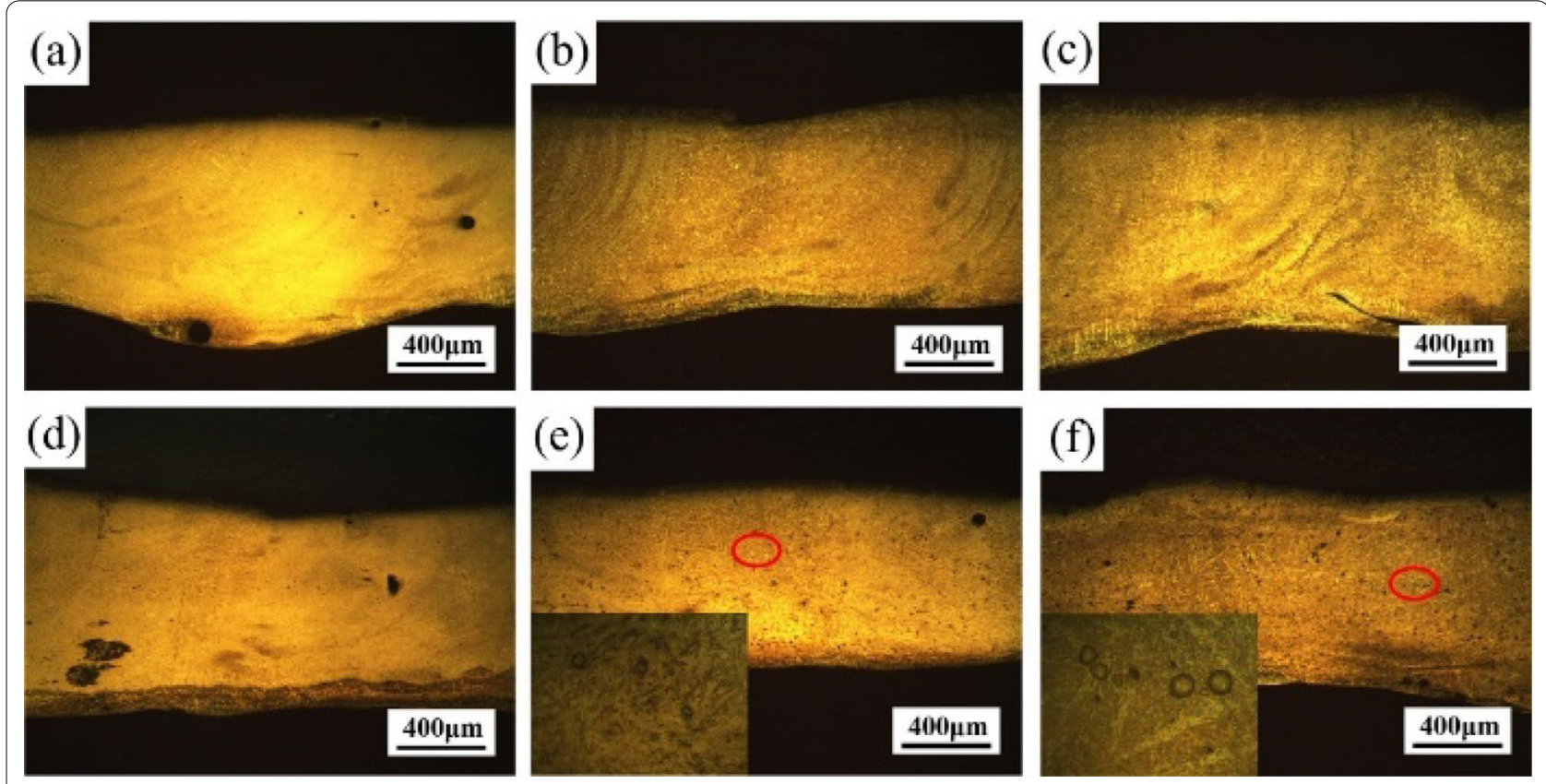

Figure 5 Cross-section morphology of nickel-based composite coating with the addition of stainless steel net: (a) Ni60 coating 8 mesh, (b) Ni60 coating +10 mesh, (c) Ni60 coating +12 mesh, (d) Ni60 coating +14 mesh, (e) Ni60 coating +24 mesh, (f) Ni60 coating +30 mesh

bubble micronuclei. The shrinkage cavity is associated with solidification shrinkage, and it is in a vacuum state at the initial stage, which creates favorable conditions for bubble precipitation.

\subsubsection{Analysis of Microhardness of the Nickel-based Composite Coating}

The microhardness profile along the depth direction of Ni60A coatings are shown in Figure 6. It can be showed that the microhardness increases with increasing mesh number of the stainless steel nets. When the stainless steel net was prefabricated on the substrate, the microhardness of the composite coating decreased. Due to the stainless steel net was melted at high temperatures, the Fe content increased. As a result, the precipitation of the hard phase was suppressed in the melt pool, which caused a reduction in the microhardness [41]. However, it was found that the microhardness of the coating was improved as the number of meshes of stainless steel net increases. When the stainless steel net with 14 mesh was prefabricated on the substrate, the highest average microhardness of the cladding layer reaches $565 \mathrm{HV}_{0.2}$, which was approximately 2.6 times higher than that of the substrate. Due the fact that as the number of the mesh of the stainless steel net increase, the diameter of wire become increasingly slender. Besides, the content of Fe element decrease with the reduction of the mass of stainless steel net per unit area prefabricating on the

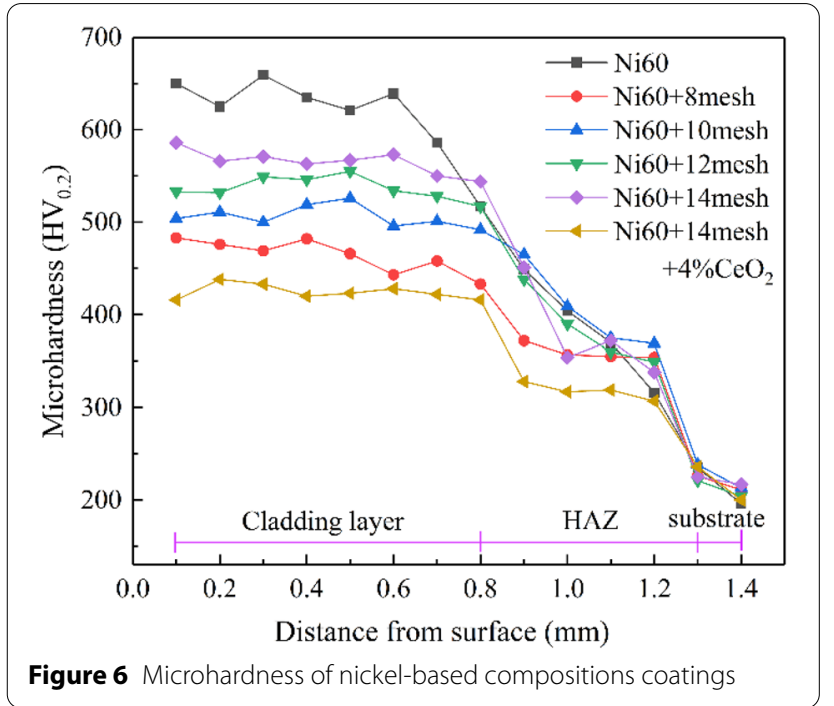

substrate, which contributes to the precipitation of the hard phase increases. When 4 wt.\% $\mathrm{CeO}_{2}$ was added in $\mathrm{Ni}$-based composite coating which the stainless steel net with 14 mesh was prefabricated on the substrate, the average hardness of the Ni-based composite coating was found to be $425 \mathrm{HV}_{0.2}$ which showed a $31 \%$ reduction compared to Ni-based composite coating without rare earth oxides, but it was still about 2 times as much as that of the 45 steel substrate. Due to the addition of $\mathrm{CeO}_{2}$, the 
laser energy absorbed by molten pool increases, increasing the convection and inducing a large number of Fe elements from the substrate to come into the molten pool [42].

\subsubsection{Analysis of Friction Coefficient of the Nickel-Based Composite Coating}

Figure 7 presents how the friction coefficient of the surface of the 45 steel and cladding layer varies with time at $3 \mathrm{~N}$ load. When the surface has undergone a relatively short running in stage, the contact area between the surface and $\mathrm{Si}_{3} \mathrm{~N}_{4}$ ball is smaller and had large contact stress. The microconvex bodies on the surfaces were abraded vigorously improving the friction coefficient. When the friction coefficient leveled off, it was demonstrated that the wear process gradually enters a stable stage. As shown in Figure 6, the 45 steel shows the highest friction coefficient, and the average friction coefficient is 0.76 . As the difference between the hardness of 45 steel and $\mathrm{Si}_{3} \mathrm{~N}_{4}$ ball is more significant, the steel surface is highly susceptible to damage. In the process of friction and wear, the production of wear debris increased frictional resistance, the friction coefficient increased. The Ni60 coating exhibited an average friction coefficient of 0.50 due to the precipitation of borides and carbides can significantly improve the hardness of the cladding coating, offering the advantage of resistance to abrasive wear. When the stainless steel net was prefabricated on the substrate with 8 mesh, 10 mesh, 12 mesh, and 14 mesh, respectively, the friction coefficient increased with the number of mesh decreasing. The average friction coefficients of Ni-based composite coating with different stainless steel net were $0.64,0.59,0.57$ and 0.46 , respectively. When the stainless steel net with 14 mesh was prefabricated on the substrate,the friction coefficient of Ni-based composite coating was reduced by $70 \%$ compared to 45 steel,

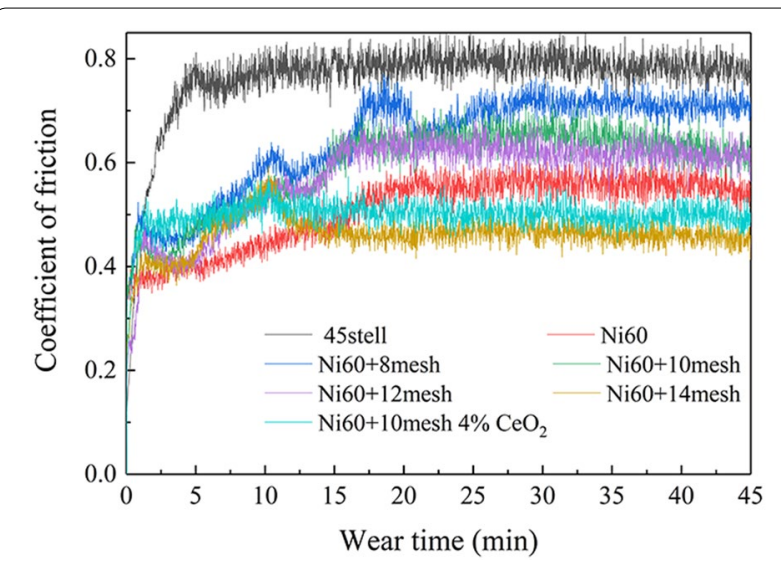

Figure 7 Friction coefficient of nickel-based composite coatings the friction coefficient was decreased by $8 \%$. The above analysis demonstrated that the Ni-based composite coating with the addition of austenitic stainless net possessed batter antiwear and friction-reduction behavior. The relative investigations reveal that the pores and cracks of the Ni-based alloy coating with the addition of 4 wt.\% $\mathrm{CeO}_{2}$ are increased compared with that of the coating without $\mathrm{CeO}_{2}$ [43]. Therefore, when the Ni-based composite coating with the addition of stainless with 14mesh and $4 \mathrm{wt} . \%$ $\mathrm{CeO}_{2}$, the average friction coefficient was 0.49. Compared with the Ni60 coating without rare earth oxides, the friction coefficient of $\mathrm{N} \mathrm{Ni-based} \mathrm{composite} \mathrm{coat-}$ ing was increased by $6.5 \%$. Compared with 45 steel, the friction coefficient of $\mathrm{Ni}$-based coating was decreased by $36 \%$.

\subsubsection{Analysis of Wear Scar Morphology and Wear Amount of Nickel-based Composite Coating}

The surface morphologies of the wear scars can be revealed by Figure 8 , the depth and width of the wear scar of the modified nickel-based composite coating were less than 45 steel, and it was demonstrated that the modified coatings are apparently much excellent wearresistant than 45 steel. Under cyclic contact stresses, the surface of 45 steel was presented severe wear, and the contact-welding was generated in a local high-temperature environment. Adhesion occurred due to the bonding of the two contact surfaces atoms. The adhesive spots were sheared off and spalled during the subsequent sliding friction. Because of the lower hardness of 45 steel, the microcracks were generated and propagated freely. Then a large number of fatigue spalling pits were found on the worn surface. The bulk of wear debris exhibited large plastic deformation after repeated rolling. As time progresses, part of the undischarged wear debris adhered to the worn surface and wear continued. According to the above analysis, the wear mechanisms of the 45 steel were fatigue wear and adhesive wear. When stainless steel net was prefabricated on the substrate, as the mesh number increased, the width of the wear scars narrower. It was demonstrated that the antifriction properties of Ni-based composite coating improve as the mesh number increased. It can be consistent with the variation of the friction coefficient of Ni-based alloy composite coating. The Ni-based alloy coating that the stainless steel net with 10 mesh was prefabricated on the substrate after the addition of the rare earth oxide $4 \mathrm{wt} . \% \mathrm{CeO}_{2}$, the width of the wear scars slightly increased, and the fatigue spalling pits were not found, which indicated that there are no large pieces of wear debris on the worn surface. In summary, when the content of $\mathrm{CeO}_{2}$ was $4 \mathrm{wt} . \%$, the nickelbased composite coating, which the stainless steel net 

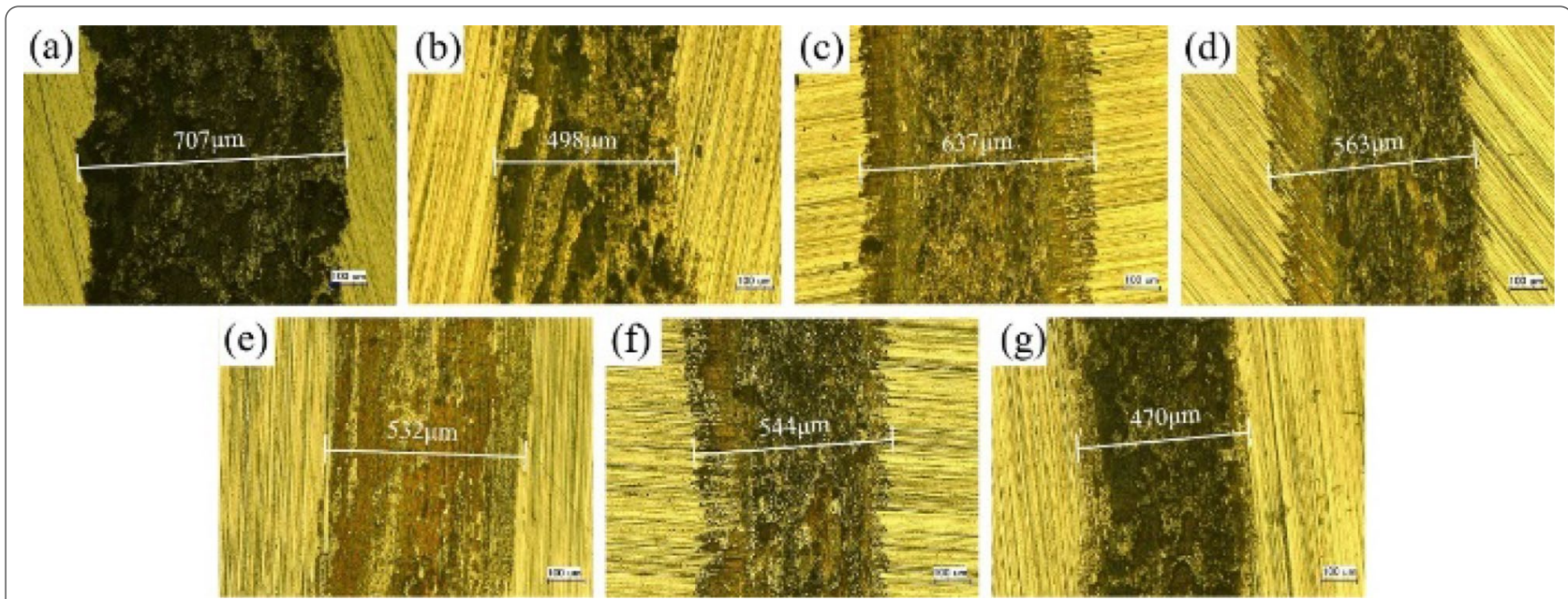

Figure 8 The surface morphologies of the wear scars of Nickel-based composite coatings: (a) 45 steel, (b) Ni60 coatings, (c) Ni60 coating + 8 mesh, (d) Ni60 coating +10 mesh, (e) Ni60 coating 12 mesh, (f) Ni60 coating +14 mesh, (g) Ni60 coating +14 mesh $+4 \% \mathrm{CeO}_{2}$

with 14 mesh was prefabricated on the substrate, showing better wear resistance.

To further investigate the wear properties of nickelbased composite coating by laser cladding, the wear volumes of the specimens were quantified separately using a surface profiler, as observed in Figure 9. In fact, in a radial section profile of erasion trace, the outside edges are significantly higher than that of the inner ones due to the plastic deformation of the wear debris produced by the surface spalling after repeated rolling. Through comparative analysis, it can be found that the 45 steel had the widest section profile of erasion trace, and the maximum depth was $7 \mu \mathrm{m}$, and the wear volume of that was $3.75 \times 10^{-5} \mathrm{~mm}^{3} \cdot \mathrm{N}^{-1} \cdot \mathrm{m}^{-1}$. The width of the erasion trace of Ni60 coating decreased significantly, and the wear volume of that was $1.47 \times 10^{-5} \mathrm{~mm}^{3} \cdot \mathrm{N}^{-1} \cdot \mathrm{m}^{-1}$, which was $60.8 \%$ lower than that of 45 steel. The width of the erasion trace of the Ni-based composite coating that the stainless steel net with 14 mesh was prefabricated on the substrate decreased significantly, and the wear volume of that was $2.89 \times 10^{-5} \mathrm{~mm}^{3} \cdot \mathrm{N}^{-1} \cdot \mathrm{m}^{-1}$, which was $22.9 \%$ lower than that of 45 steel. When the rare earth oxide 4 wt.\% $\mathrm{CeO}_{2}$ was added to it, the depth of the erasion trace of Ni-based composite coating decreased significantly, and the wear volume of that was $0.56 \times 10^{-5} \mathrm{~mm}^{3} \cdot \mathrm{N}^{-1} \cdot \mathrm{m}^{-1}$, which was $80.6 \%$ lower than that of Ni-based coating without rare earth oxide, and 85.1\% lower than that of 45 steel substrate. Although the rare earth oxide $4 \mathrm{wt} . \% \mathrm{CeO}_{2}$ was added in the $\mathrm{Ni}$ based composite coating which the stainless steel net with 14 mesh was prefabricated on the substrate reducing the microhardness, the abrasion wears resistance of it improved substantially. This is consistent with previous studies [44, 45], indicating that there is no correlation between wear resistance and hardness in multiphase materials. Hardness describes only the hard body's penetration resistance, but it does not include mechanisms of formation and propagation of cracks which finally lead to the separation of the material [46]. The wear resistance of multiphase materials was controlled not only by the hard phase of materials but also by the strength and toughness of the matrix phase.

\subsection{Microstructure and Phase Analysis of $\mathrm{CeO}_{2}$ to Nickel-based Composite Coating}

4.2.1 XRD Phase Analysis of Nickel-based Composite Coating

To further investigate the mechanism of reduction of hardness and increase of wear resistance of Ni-based composited coating with the addition of $4 \mathrm{wt} . \% \mathrm{CeO}_{2}$, Figure 10 exhibits the phase composition of materials using the XRD technique. Ni60 coating was mainly composed of the matrix $\gamma-(\mathrm{Ni}, \mathrm{Fe})$ solid solution and the reinforcement phases such as $\mathrm{M}_{23} \mathrm{C}_{6}, \mathrm{M}_{7} \mathrm{C}_{3}$ and hard phase $\mathrm{CrB}, \mathrm{CeCr}_{2} \mathrm{~B}$. Due to the high contents of $\mathrm{Fe}$, $\mathrm{Ni}$ and $\mathrm{Cr}$ of 304 stainless steel, peaks of nickel-based composite coating that the stainless steel net with 14 mesh was prefabricated on the substrate intensified at $2 \theta=44.1^{\circ}$. But there was no difference in phase composition compared to Ni60 coating. The appearance of peak broadening at the diffraction angle of about $51.0^{\circ}$ and $75.3^{\circ}$ was obtained through the addition of the rare earth oxide 4 wt.\% $\mathrm{CeO}_{2}$ into $\mathrm{Ni}$-based composite coating, and there are mainly hard phase $\mathrm{CrB}$ and eutectic phase $\mathrm{M}_{23} \mathrm{C}_{7}$, at the same time, a new phase of $\mathrm{CeCr}_{2} \mathrm{~B}$ appeared. 

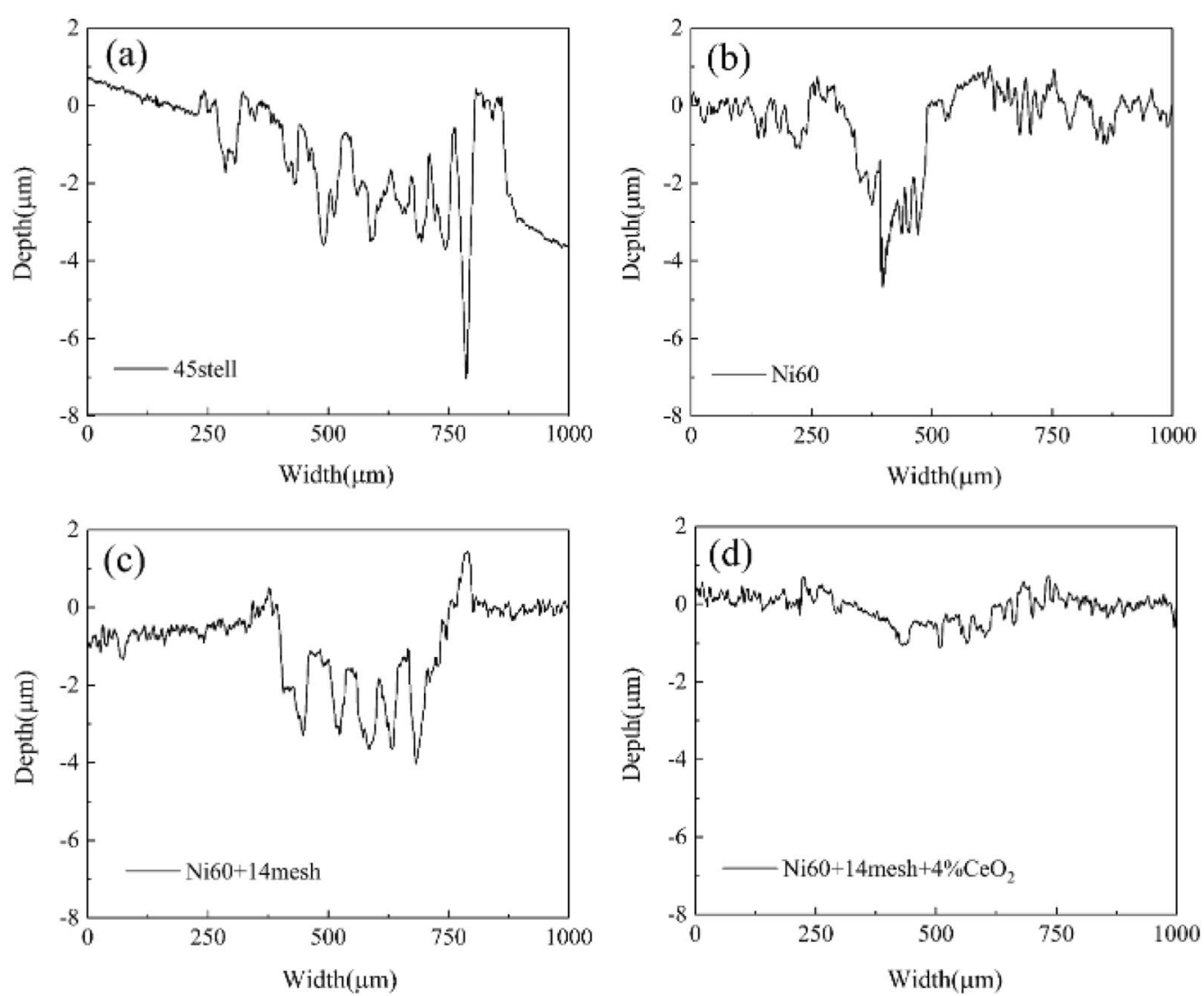

Figure 9 Radial wear scar profile: (a) 45 steel, (b) Ni60 coatings, (c) Ni60 coating 14 mesh, (d) Ni60 coating +14 mesh $+4 \% \mathrm{CeO}_{2}$

\subsubsection{Microstructure Analysis of Nickel-based Composite Coating}

Figure 11 and Table 5 reveal the micro-morphologies and the constituent phases of the nickel-based composite

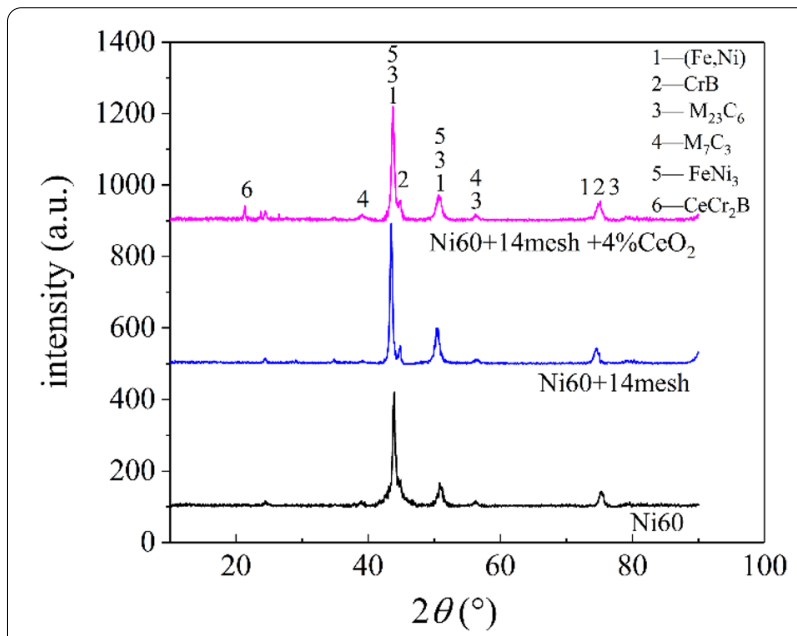

Figure 10 XRD phase diagram of nickel-based composite coating coatings. Figure 11(a) shows that nickel-based composite coating mainly consists of bulk phase with irregular shape $A$, interdendritic eutectics with the rod-shaped structure B cellular dendrite phase C. Since B and C belong to low atomic number elements, they can not be determined by EDS analysis. The estimation of the constituent phases can be done as follows. Through XRD analysis and reference to the relevant literatures, the following can be inferred. The bulk eutectic contains a high concentration of $\mathrm{Ni}, \mathrm{Cr}$, and $\mathrm{Fe}$, a slight amount of $\mathrm{C}$ elements, and $\mathrm{B}$ poor. It could be inferred that this phase is probably borides $\mathrm{CrB}$. The interdendritic eutectics with the rod-shaped structure are identified as $\gamma$ - $(\mathrm{Fe}$, $\mathrm{Ni})+\mathrm{M}_{7} \mathrm{C}_{3}(\mathrm{M}=\mathrm{Fe}, \mathrm{Ni}, \mathrm{Cr})$ with fewer quantities of $\mathrm{C}$. As shown in Table 3, the relatively high content of $\mathrm{Ni}$ is overwhelmingly in cellular dendrite phase in which relatively low contents of $\mathrm{C}$ and $\mathrm{Cr}$ are dissolved. It can be confirmed that the cellular dendrite is the primary $\gamma$ - $(\mathrm{Fe}$, $\mathrm{Ni)}$ solid solution.

Figure 11(b) shows that nickel-based composite coating with the addition of $4 \mathrm{wt} . \% \mathrm{CeO}_{2}$ mainly consists of blocky phase $\mathrm{D}$, flake-like eutectic phase $\mathrm{E}$, cellular dendrite phase F. Compared to coating without rare earth 

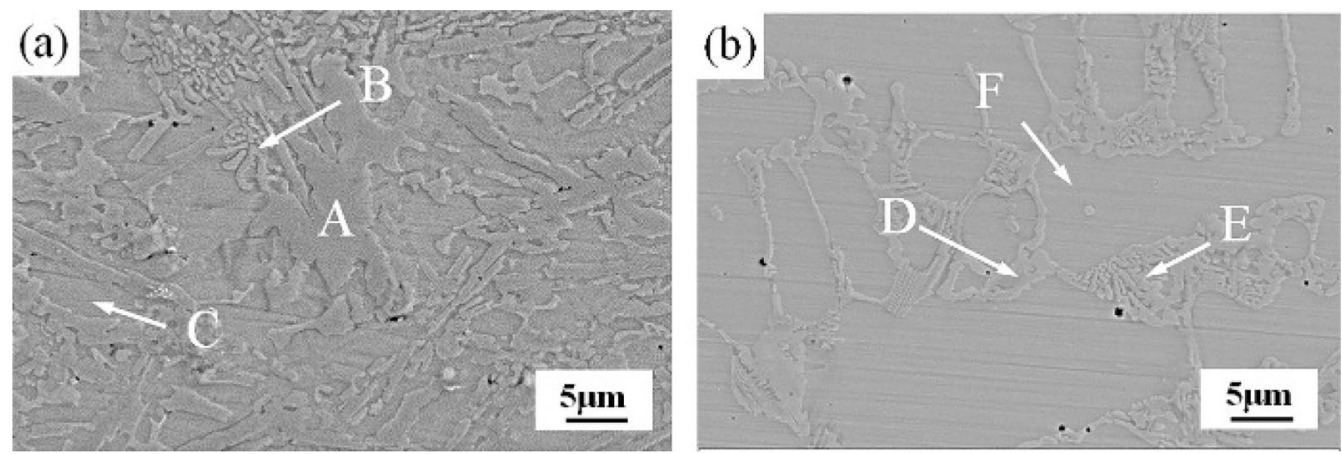

Figure 11 (a) Nickel-based composite coating +14 mesh, (b) Nickel-based composite coating +14 mesh $+4 \% \mathrm{CeO}_{2}$

Table 5 EDS composition analysis of Nickel-based composite coating +14 mesh and Nickel-based composite coating +14 mesh + $4 \% \mathrm{CeO}_{2}$ (mass fraction (\%))

\begin{tabular}{|c|c|c|c|c|c|c|c|}
\hline Location & B & C & $\mathrm{Cr}$ & $\mathrm{Fe}$ & $\mathrm{Ni}$ & w & $\mathrm{Si}$ \\
\hline A & 10.45 & 6.08 & 31.26 & 39.06 & 9.79 & 1.14 & \\
\hline B & & 9.7 & 15.93 & 33.62 & 34.36 & & 2.24 \\
\hline C & & 7.83 & 4.23 & 34.64 & 47.19 & & 3.42 \\
\hline D & 7.16 & 9.13 & 9.67 & 66.11 & 7.37 & 0.29 & 0.27 \\
\hline $\mathrm{E}$ & & 10.35 & 5.01 & 68.58 & 14.79 & & 1.27 \\
\hline $\mathrm{F}$ & & 8.64 & 5.06 & 71.42 & 13.79 & & 1.09 \\
\hline
\end{tabular}

oxide, the Fe element content increased, and the Cr element content decreased. On the one hand, the laser energy absorbed by the molten pool increases due to the addition of $\mathrm{CeO}_{2}$, increasing the convection and inducing the excessive melting of the substrate [42]. It contributes to an amount of Fe coming into the molten pool. On the other hand, $\mathrm{Fe}$ and $\mathrm{Cr}$ belong to the elements of the third period, and the radius of the Fe atom is close to that of the $\mathrm{Cr}$ atom. When the Fe concentration is higher, the $\mathrm{Cr}$ atoms are replaced with $\mathrm{Fe}$ to form a solid solution phase. A new phase $\mathrm{CeCr}_{2} \mathrm{~B}$ is formed after the addition of $\mathrm{CeO}_{2}$ since the addition of $\mathrm{CeO}_{2}$ are comparatively less in quantity and the finite dimensions of the probe, the element of Ce fails to detect. Combined with XRD analysis and relevant references, the blocky phase (marked with $\mathrm{D}$ in Figure 11(b)) may be identified as $\mathrm{CrB}$ with significant quantities of Fe. The flake-like eutectic phase (marked with $\mathrm{E}$ in Figure 10(b)) may be identified as $\gamma-(\mathrm{Fe}, \mathrm{Ni})+$ $\mathrm{M}_{23} \mathrm{C}_{7}(\mathrm{M}=\mathrm{Fe}, \mathrm{Ni}, \mathrm{Cr})$ eutectics with small quantities of $\mathrm{Si}$. The cellular dendrite phase may be identified as $\gamma$ - $(\mathrm{Fe}$, $\mathrm{Ni}$ ) solid solution with small quantities of $\mathrm{C}, \mathrm{Cr}$ and $\mathrm{Si}$.

Through comparative analysis, when 4 wt.\% $\mathrm{CeO}_{2}$ was added in Ni-based composite coating which the stainless steel net with 14 mesh was prefabricated on the substrate, the size of the cellular dendrons increases and the resistance of the crystal boundary reduces. When an external force was applied, the plasticity distortion was very easy to go through the crystal boundary from one crystal grain to another [47]. Besides, hardness describes only the hard body's resistance to penetration [46]. The hardness of the coating was reduced. When the cladding layer was subjected to thermal stress, part of the internal stress will be removed by plastic deformation, which would reduce the cracking tendency. It can be seen from Figure 11(b) that the size of the bulk phase decrease. When the melt pool temperature is higher than $2050{ }^{\circ} \mathrm{C}$, $\mathrm{CeO}_{2}$ could be decomposed to $\mathrm{Ce}$ ion. In addition, $\mathrm{Ce}$ enriches as an inner adsorption element mainly at the grain boundary, which decreases the interfacial energy and Gibbs free energy of the cladding layer, and reduces the driving force for crystal growth, thereby hindering the growth of crystals [48]. From this, hard phases $\left(\mathrm{CeCr}_{2} \mathrm{~B}\right)$ were distributed at grain boundaries of bulk phases. The ductile phase $\gamma-(\mathrm{Fe}, \mathrm{Ni})$ was precipitated after the primary hard phase during laser cladding, and the ductile phase was prone to inhibition, so the amount of the hard phase decreased would increase the number of ductile phases. When the surface layer was subjected to external force, it can reduce the probability of damage to the surface layer in an elastic deformation manner within a 
certain range. The softer matrix phase was worn, and the hard phase, which plays a certain supporting and bearing role was not easy to be peeled off due to its small size, thus, reducing the viscous force. In addition, the softer matrix phase acted as inlaying wear debris and hard particle, therefore the wear resistance was improved greatly.

\section{Conclusions}

(1) The fracture criterion of the nickel-based coating was presented basing on thermoelasticity theory and fracture mechanics. Factors that influence the Microscopic cracks included material thermophysical parameters $(E, \Delta \alpha, \Delta T)$, specimen length and critical crack opening displacement when cracking occurs.

(2) The difference in thermal expansion coefficient $\Delta \alpha$ was reduced by prefabricating an austenitic stainless net on the surface of the substrate, and a significant number of the transverse and longitudinal cracks were disappeared in the Ni-based coating.

(3) As the number of meshes of stainless steel net increased, the average microhardness of the nickelbased composite coating improved, and the friction coefficient decreased. When the stainless steel net with 14 mesh was prefabricated on the substrate, the highest average microhardness of nickel composite coating was $565 \mathrm{HV}$ which was 2.6 times higher than that of the substrate and the average friction coefficient of Ni-based composite coating was reduced by $70 \%$ compared to 45 steel. Comparing with the Ni60 coating, the friction coefficient was decreased by $8 \%$.

(4) After the 4 wt.\% $\mathrm{CeO}_{2}$ was added to Ni-based composite coating that the stainless steel net was prefabricated on the substrate with 14 mesh, comparing with coating without rare earth oxides, the average hardness showed a $36 \%$ reduction and the average coefficient of friction increased by $6.5 \%$. But the wear resistance improved substantially. The wear volume of that was $0.56 \times 10^{-5} \mathrm{~mm}^{3} \cdot \mathrm{N}^{-1} \cdot \mathrm{m}^{-1}$, which was $80.6 \%$ lower than that of Ni-based coating without rare earth oxide, and $85.1 \%$ lower than that of 45 steel substrate.

\section{Acknowledgements}

Not applicable.

\section{Authors' Contributions}

$Z Y, L L, D Z$ was in charge of the whole trial; ZY, LL wrote the manuscript; GSh, GY, ZX, ZZ assisted with sampling and laboratory analyses. All authors read and approved the final manuscript.

\section{Authors' Information}

Zhenglei Yu, born in 1984, is currently an associate professor at Key Lab of Bionic Engineering, Ministry of Education, Jilin University, China. He received his PhD degree from Jilin University, China, in 2014. His research interests include bionic structure design and additive manufacturing.

Lunxiang Li, born in 1993, is currently a PhD candidate at College of Mechanical and Electric Engineering, Changchun University of Science and Technology, China. He received his master's degree from Liaoning University of Technology, China. in 2020. His research interests include bionic structure design and additive manufacturing.

Deqiang Zhang, born in 1964, is currently a professor at College of Mechanical Engineering and Automation, Liaoning University of Technology, China. He received his master's degree from Harbin Institute of Technology, China. in 1995. His research interests include numerical technology and laser cladding.

Guangfeng Shi, born in 1981, is currently a professor at College of Mechanical and Electric Engineering, Changchun University of Science and Technology, China. He received his PhD degree from Changchun Institute of Optics, Fine Mechanics and Physics, Chinese Academy of Sciences, China. in 2010. His research interests include Precision/Ultra-precision machining and testing and equipment.

Guang Yang, born in 1978, is currently an associate professor at Key Laboratory of Fundamental Science for National Defense of Aeronautical Digital Manufacturing Process, Shenyang Aerospace University, China. He received his doctor degree from Shenyang Institute of Automation Chinese Academy of Sciences, China, in 2010. His research interests include additive manufacture and major rare parts repair

Zezhou Xu, born in 1995, is currently a PhD candidate at Key Lab of Bionic Engineering, Ministry of Education, Jilin University, China. He received his master's degree from University of Science and Technology Liaoning, China, in 2020. His research interests include bionic structure design and additive manufacturing.

Zhihui Zhang, born in 1976, is currently a professor at Key Lab of Bionic Engineering, Ministry of Education, Jilin University, China. He received his master's degree from Jilin University, China. in 2007. His research interests include bionic structure design and additive manufacturing.

\section{Funding}

Supported by National Key R\&D Program of China (Grant No.

2018YFB1 105100), National Natural Science Foundation of China (Grant No. 51975246), Jilin Provincial Science and Technology Development Plan of China (Grant Nos. 20190302123GX, YDZJ202101ZYTS134), the State Key Laboratory of Automotive Simulation and Control - ziyoutansuoxiangmu (202013), Interdisciplinary Research Funding Program for Doctoral Candidates of Jilin University (101832020DJX052), Science and Technology Project of Jilin Education Department (Grant No. JJKH20200958KJ), Program for JLU Science and Technology Innovative Research Team (Grant No. 2019TD-34), and the Advanced Manufacturing Project of Provincial School Construction of Jilin Province of China (Grant No. SXGJSF2017-2).

\section{Competing Interests}

The authors declare no competing financial interests.

\section{Author Details}

${ }^{1}$ Key Lab of Bionic Engineering, Ministry of Education, Jilin University, Changchun 130022, China. ${ }^{2}$ State Key Laboratory of Automotive Simulation and Control, Jilin University, Changchun 130022, China. ${ }^{3}$ College of Mechanical and Electric Engineering, Changchun University of Science and Technology, Changchun 130022, China. ${ }^{4}$ College of Mechanical Engineering and Automation, Liaoning University of Technology, Jinzhou 121001, China. ${ }^{5}$ Key Laboratory of Fundamental Science for National Defense of Aeronautical Digital Manufacturing Process, Shenyang Aerospace University, Shenyang 110136, China.

Received: 12 March 2021 Revised: 18 July 2021 Accepted: 11 August 2021 Published online: 25 September 2021 


\section{References}

[1] J M S Sousa, A S P Pereira, M Pereira, et al. Influence of laser metal deposition direction in the abrasive and adhesive wear resistance of $\mathrm{Ni}-\mathrm{Cr}-\mathrm{B}-\mathrm{Si}$ coatings. Journal of Laser Applications, 2020, 32(2): 22045.

[2] K Holmberg, A Erdemir. Influence of tribology on global energy consumption, costs and emissions. Friction, 2017, 5(3): 263-284.

[3] J M S d Sousa, F Ratusznei, M Pereira, et al. Abrasion resistance of $\mathrm{Ni}-\mathrm{Cr}$ B-Si coating deposited by laser cladding process. Tribology International, 2020: 143.

[4] GXYang, M Wang, Q Li, et al. Methodology to evaluate fatigue damage of high-speed train welded bogie frames based on on-track dynamic stress test data. Chinese Journal of Mechanical Engineering, 2019, 32: 8.

[5] W H Huang, Z G Jiang, TWang, et al. Remanufacturing scheme design for used parts based on incomplete information reconstruction. Chinese Journal of Mechanical Engineering, 2020, 33(1): 14.

[6] L Zhai, Q Wang, J Zhang, et al. Effect of alternating current electric field on microstructure and properties of laser cladding Ni-Cr-B-Si coating. Ceramics International, 2019, 45(14): 16873-16879.

[7] Y H Lin, X L Ping, J C Kuang, et al. Improving the microstructure and mechanical properties of laser cladded Ni-based alloy coatings by changing their composition: A review. Reviews on Advanced Materials Science, 2020, 59(1): 340-351.

[8] TY Geng, C S Wang. Influence of graphene sheet on microstructure and properties of $\mathrm{Ni}$-based alloy coatings prepared by laser cladding. Materials Science, 2019, 25(3): 252-258.

[9] $\mathrm{Y} \mathrm{Hu}, \mathrm{W}$ Cong. A review on laser deposition-additive manufacturing of ceramics and ceramic reinforced metal matrix composites. Ceramics International, 2018, 44(17): 20599-20612.

[10] M Elahinia, N S Moghaddam, M T Andani, et al. Fabrication of NiTi through additive manufacturing: A review. Progress in Materials Science, 2016, 83: 630-663.

[11] A N Jinoop, C P Paul, K S Bindra. Laser-assisted directed energy deposition of nickel super alloys: A review. Proceedings of the Institution of Mechanical Engineers Part L-Journal of Materials-Design and Applications, 2019, 233(11): 2376-2400.

[12] E Hosseini, V A Popovich. A review of mechanical properties of additively manufactured Inconel 718. Additive Manufacturing, 2019: 30.

[13] Y N Aditya, T D Srichandra, M Tak, et al. To study the laser cladding of ultra high strength AerMet-100 alloy powder on AISI-4340 steel for repair and refurbishment. Materials Today-Proceedings, 2021, 41: 1146-1155.

[14] N Ahmed. Direct metal fabrication in rapid prototyping: A review. Journal of Manufacturing Processes, 2019, 42: 167-191.

[15] N Jeyaprakash, C H Yang. Microstructure and wear behaviour of SS420 micron layers on Ti-6Al-4V substrate using laser cladding process. Transactions of the Indian Institute of Metals, 2020, 73(6): 1527-1533.

[16] X Q Zhang, H B Chen, L M Xu, et al. Cracking mechanism and susceptibility of laser melting deposited Inconel 738 superalloy. Materials \& Design, 2019, 183: 108105.

[17] L D Zhu, P S Xue, Q Lan, et al. Recent research and development status of laser cladding: A review. Optics and Laser Technology, 2021: 138.

[18] Y F Shen, H G Fu, X L Pan, et al. Effect of process parameters and niobium carbide addition on microstructure and wear resistance of laser cladding nickel-based alloy coatings. Materialwissenschaft und Werkstofftechnik, 2020, 51(1): 54-65

[19] CWang, Y Gao, Z Zeng, et al. Effect of rare-earth on friction and wear properties of laser cladding Ni-based coatings on 6063Al. Journal of Alloys and Compounds, 2017, 727: 278-285.

[20] M M Quazi, M A Fazal, A S M A Haseeb, et al. Effect of rare earth elements and their oxides on tribo-mechanical performance of laser claddings: A review. Journal of Rare Earths, 2016, 34(6): 549-564. (in Chinese)

[21] N Zhao, Li Tao, Hui Guo, et al. Microstructure and wear resistance of laser cladded Ni-based coatings with nanometer $\mathrm{La}_{2} \mathrm{O}_{3}$ addition. Rare Metal Materials and Engineering, 2017, 46(8): 2092-2096. (in Chinese)

[22] K K Tang, Z X Ding, C Li. et al. Microstructure and abrasive wear resistance of Nano-WC reinforced Ni-based alloy spray-melted coatings. Surface Technology, 2017, 46(8): 27-32. (in Chinese)

[23] I Hemmati, V Ocelík, J T M D Hosson. Dilution effects in laser cladding of Ni-Cr-B-Si-C hardfacing alloys. Materials Letters, 2012, 84: 69-72.
[24] I Hemmati, V Ocelík, J T M D Hosson. Effects of the alloy composition on phase constitution and properties of laser deposited Ni-Cr-B-Si coatings. Physics Procedia, 2013, 41: 302-311.

[25] I Hemmati, V Ocelík, J T M D Hosson. Toughening mechanism for Ni-Cr-BSi-C laser deposited coatings. Materials Science and Engineering: A, 2013, 582: 305-315

[26] M R Fernández, A García, J M Cuetos, et al. Effect of actual WC content on the reciprocating wear of a laser cladding $\mathrm{NiCrBSi}$ alloy reinforced with WC. Wear, 2015, 324: 80-89.

[27] J S Xu, X C Zhang, F Z Xuan, et al. Tensile properties and fracture behavior of laser cladded WC/Ni composite coatings with different contents of WC particle studied by in-situ tensile testing. Materials Science and Engineering: $A, 2013,560:$ 744-751.

[28] Q L Dai, C B Luo, F Y You. Crack restraining methods and their effects on the microstructures and properties of laser cladded WC/Fe coatings. Materials, 2018, 11(12): 2541.

[29] L Y Zhong, L W Ning, W B Ren, et al. Crack analysis and control of laser cladding inconel718 alloy. Surface Technology, 2020, 49(9): 233-243. (in Chinese)

[30] HY Qi, M K Azer, A Ritter. Studies of standard heat treatment effects on microstructure and mechanical properties of laser net shape manufactured inconel 718. Metallurgical and Materials Transactions A, 2009, 40(10): 2410-2422.

[31] L Thijs, F Verhaeghe, T Craeghs, et al. A study of the microstructural evolution during selective laser melting of Ti-6Al-4V. Acta Materialia, 2010, 58(9): 3303-3312

[32] L Reddy, S P Preston, P H Shipway, et al. Process parameter optimisation of laser clad iron based alloy: Predictive models of deposition efficiency, porosity and dilution. Surface and Coatings Technology, 2018, 349: 198-207.

[33] G Xu, M Kutsuna, Z Liu, et al. Characteristics of Ni-based coating layer formed by laser and plasma cladding processes. Materials Science and Engineering: $A, 2006,417(1-2): 63-72$

[34] X L Wang, D W Deng, M Qi, et al. Influences of deposition strategies and oblique angle on properties of AISI316L stainless steel oblique thinwalled part by direct laser fabrication. Optics \& Laser Technology, 2016, 80: 138-144.

[35] Z P Wu, T Li, Q Li, et al. Process optimization of laser cladding Ni60A alloy coating in remanufacturing. Optics \& Laser Technology, 2019, 120: 105718.

[36] F Y Niu, D J Wu, S Yan, et al. Process optimization for suppressing cracks in laser engineered net shaping of $\mathrm{Al}_{2} \mathrm{O}_{3}$ ceramics. JOM, 2016, 69(3): 557-562.

[37] J Cheng, S Zhao. Fracture mechanics. Beijing: Science Press, 2006. (in Chinese)

[38] Z Zhang, R Kovacevic. A thermo-mechanical model for simulating the temperature and stress distribution during laser cladding process. The International Journal of Advanced Manufacturing Technology, 2019, 102(14): $457-472$

[39] C Shang, CWang, C Li, et al. Eliminating the crack of laser 3D printed functionally graded material from TA15 to inconel718 by base preheating. Optics \& Laser Technology, 2020: 126.

[40] X Lu, X Lin, M Chiumenti, et al. Finite element analysis and experimenta validation of the thermomechanical behavior in laser solid forming of Ti-6Al-4V. Additive Manufacturing, 2018, 21: 30-40.

[41] J Zhang, Y Hu, X J Tan, et al. Microstructure and high temperature tribological behavior of laser cladding Ni60A alloys coatings on 45 steel substrate. Transactions of Nonferrous Metals Society of China, 2015, 25(5): 1525-1532. (in Chinese)

[42] D Shu, X Cui, Z Li, et al. Effect of the rare earth oxide $\mathrm{CeO}_{2}$ on the microstructure and properties of the Nano-WC-reinforced Ni-based composite coating. Metals, 2020, 10(3): 383

[43] CWang, Y Gao, G Zhang. Effect of $\mathrm{CeO}_{2}$ addition on interface structure and corrosion resistance of laser cladding additive manufactured Ni60 alloy layers on the surface of Al alloys. Rare Metal Materials and Engineering, 2017, 46(8): 2306-2312. (in Chinese)

[44] TYu, Q L Deng, G Dong, et al. Influence of Ta on crack susceptibility and mechanical properties of laser clad Ni-based coating. Journal of Mechanical Engineering, 2011, 47(22): 25-30. (in Chinese) 
[45] F Findik. Latest progress on tribological properties of industrial materials. Materials \& Design, 2014, 57: 218-244.

[46] E Pagounis, V K Lindroos, M Talvitie. Influence of matrix structure on the abrasion wear resistance and toughness of a hot isostatic pressed white iron matrix composite. Metallurgical and Materials Transactions A, 1996, 27(12): 4183-4191.
[47] F X Huang, Z H Jiang, X M Liu, et al. Effects of process parameters on microstructure and hardness of layers by laser cladding. ISIJ International, 2011, 51(3): 441-447.

[48] Y Tang, R Hanus, S W Chen, et al. Solubility design leading to high figure of merit in low-cost Ce-CoSb 3 skutterudites. Nature Communications, 2015, 6: 7584 .

\section{Submit your manuscript to a SpringerOpen ${ }^{\circ}$ journal and benefit from:}

- Convenient online submission

- Rigorous peer review

- Open access: articles freely available online

- High visibility within the field

- Retaining the copyright to your article

Submit your next manuscript at $\boldsymbol{\sim}$ springeropen.com 